\title{
SPACE TECHNOLOGY FOR BOOK PRESERVATION
}

A cooperative program with the Library of Congress aimed at
extending the useful lives of books exemplifies NASA
technology demonstrations of better ways to meet public needs

$\Delta$ mong the many facilities at A NASA's Goddard Space Flight Center, located in the Maryland suburbs not far from Washington, D.C., is a large vacuum chamber normally used to simulate airless space for tests of satellites and their instruments. In a two-week long run last fall, however, the chamber had quite a different payload: books, more than 500 cartons of them, some 5,000 books in all. They were undergoing vacuum treatment with a gaseous chemical in a feasibility test of a process developed by the Library of Congress for extending the lives of books and valuable documents.

The Library of Congress has some 20 million books and almost a third of them have deteriorated considerably. Yet some of the Library's oldest books are still in excellent condition. The reason is that they were printed on handmade paper, made of rags, that does not degrade as rapidly as modern paper. Handmade paper gave way more than a century ago to machine-processed paper made from ground wood pulp. Today's paper manufacturing process employs chlorine bleaching and alum as part of the "sizing," which helps keep print ink from blurring on the paper. This chemistry introduces acid that in time makes

Technicians prepare to remove some 5,000 books from the vacuum chamber at Goddard Space Flight Center after a chamber run in which the books were chemically treated to neutralize the acid in the book paper. The deacidification process, developed by the Library of Congress, is designed to extend book lifetimes five to six times.

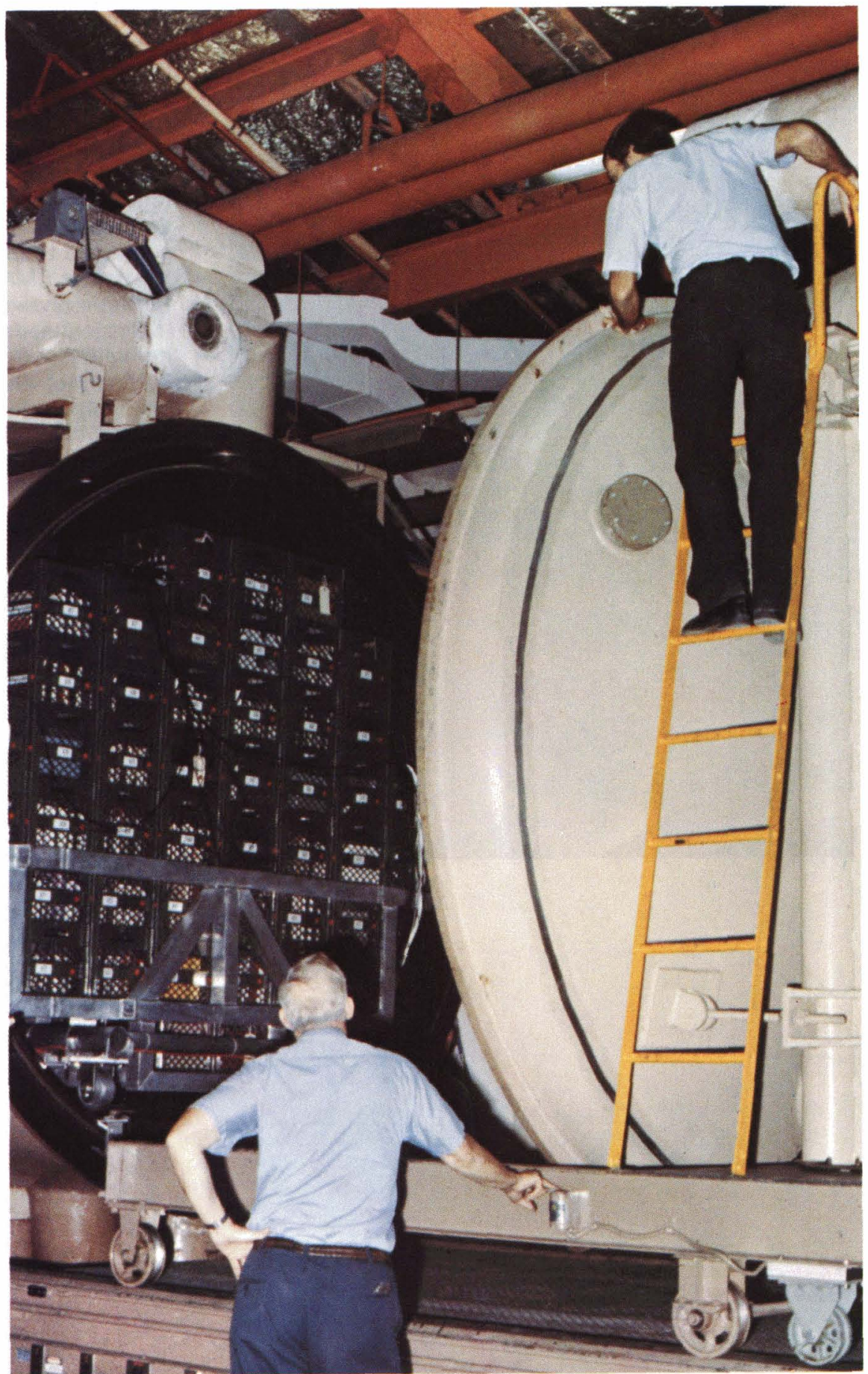




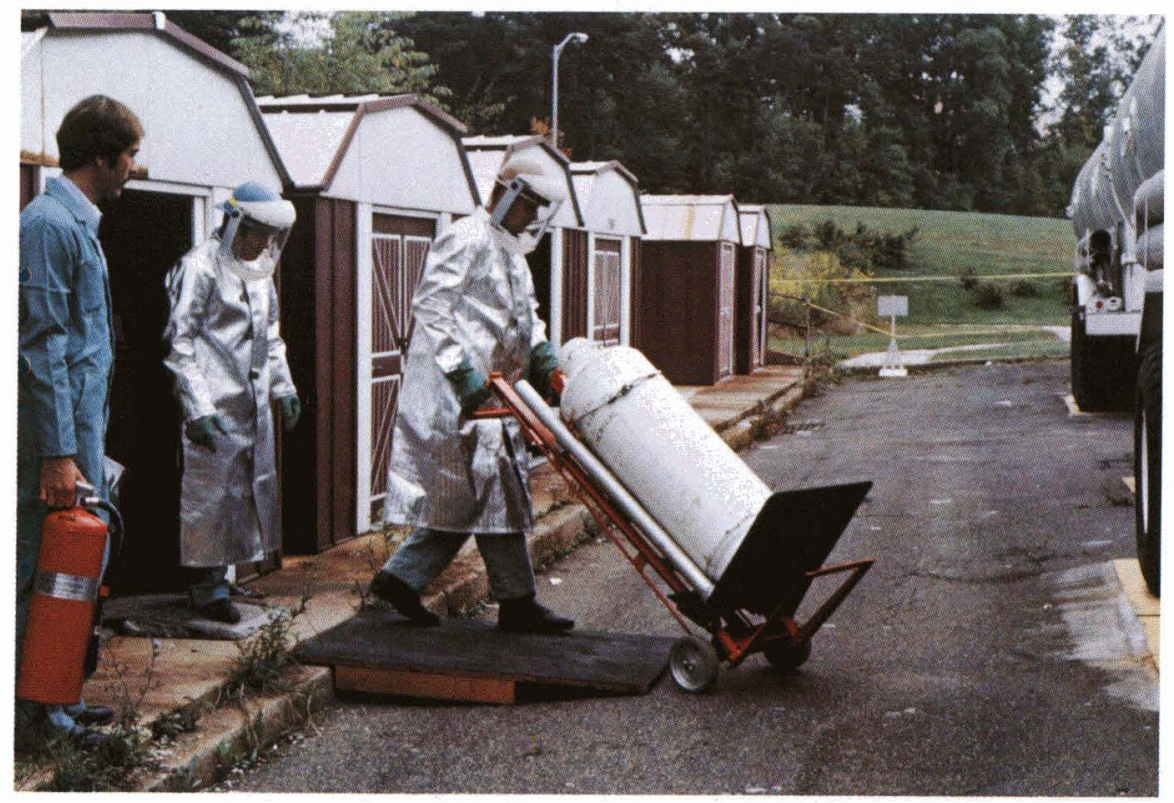

pages so brittle they crumble when handled. As a result, the lifetimes of most books printed in the 20th century are on the order of 25 to 100 years, where many older books have survived for centuries.

Obviously, a means of "deacidifying" books on a large, economically-viable scale is of great interest to research libraries and documentation centers. The Library of Congress, after several years of experimentation, has patented a process it considers almost ready for commercial use. Called vapor phased deacidification, it involves use of a chemical vapor known as DEZ (for diethyl zinc) that neutralizes the acid and deposits on book pages an alkaline reserve to combat their later return to acid condition; in this manner, the Library hopes to extend book lives at least five to six times their anticipated span. DEZ, however, is a highly volatile substance that flames instantaneously on contact with oxygen; thus, book processing with DEZ must be accomplished in an airless environment.

The Library originally tested the process in an ordinary pressure cooker, treating only a few books. Later, 400 books at a time were successfully treated in a series of experiments at Valley Forge, Pennsylvania; these tests were conducted in a vacuum chamber operated by General Electric Company's Space Systems Division. The Goddard vacuum chamber used in the 1982 tests served multiple purposes: it created an environment where DEZ could do its job without the presence of oxygen; it removed moisture-600 pounds of it-from the books, a necessary preliminary step in the process; and it provided a means of determining the efficacy of the process in treating much larger numbers of books in a single chamber run. vacuum chamber, Goddard Space Flight Center and its support contractor, Northrop Services, Inc. contributed expertise in vacuum technology and handling of volatile substances; they also originated procedures and process-monitoring techniques for the test run that will provide a technology base for development of safe deacidification on a large-scale basis.

Last year's test at Goddard demonstrated that 5,000 books can be treated at once and it appears feasible that, given a large enough chamber, it would be possible to handle $15-20,000$ books on a single run; treatment on that scale would bring the cost down to a few dollars per book. The Library of Congress development plan envisions eventual operation of a facility near Washington, D.C. for processing half a million books a year; the Library would also license the technology to private companies offering commercial deacidification services to many other libraries. Evidence of the interest in the process is the fact that the libraries of Columbia, Yale and Stanford universities, the New England Document Conservation Center, the New York Public Library and the National Archives all contributed books for the Goddard test.

The assistance provided the Library of Congress typifies a special facet of NASA's Technology Utilization Program: demonstrations
In addition to supplying the
Book processing must be accomplished in an airless environment-a vacuum chamber-because the chemical vapor used is a highly volatile substance. Called DEZ, it is shown being transported carefully to the Goddard vacuum facility.

to show how advanced technology may help solve major problems or create better ways of meeting public needs. Spinoff products sometimes emerge from such demonstrations, but product commercialization is not the primary aim. NASA's intent is to expand public awareness of advantageous technology and inspire its broader application by government agencies, communities, medical institutions and other organizations. Additional examples of technology demonstrations are contained on the following pages

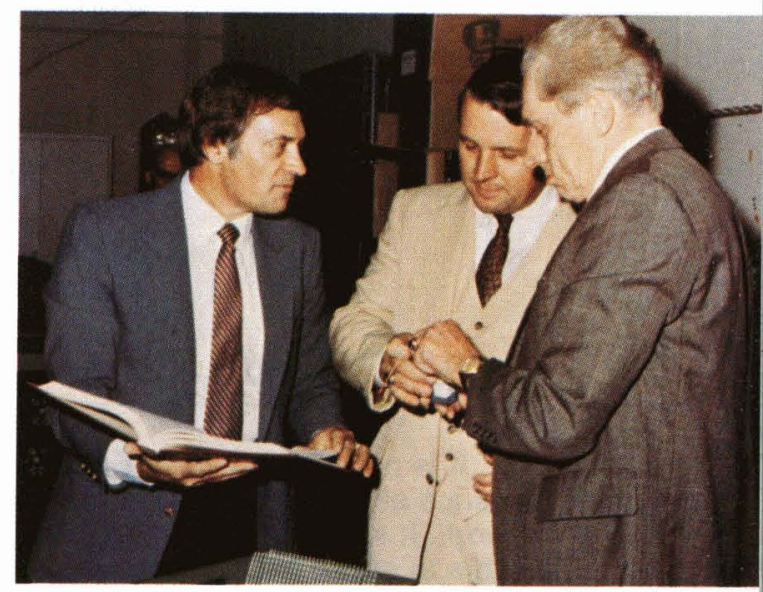

Dr. Peter Sparks (center), Director for Preservation, Library of Congress, is performing a post-treatment test on a sample book; the paper's reaction to the chemical he is applying shows whether the acid was properly neutralized. Sparks is flanked by Henry Maurer, NASA project manager, and William Welsh, Deputy Librarian of Congress. 